\title{
Crystal Structure of $\mathrm{FePb}_{4} \mathrm{Sb}_{6} \mathrm{Se}_{14}$ and its Structural Relationship with $\mathrm{FePb}_{3} \mathrm{Sb}_{4} \mathrm{Se}_{10}$
}

\author{
Pierre F. P. Poudeu, ${ }^{*[a]}$ Honore Djieutedjeu, ${ }^{[a]}$ and Pranati Sahoo ${ }^{[a]}$
}

Keywords: Crystal structure; Iron selenide; Main group elements; Seleno Jamesonite; Semiconductors

\begin{abstract}
Single crystals of $\mathrm{FePb}_{4} \mathrm{Sb}_{6} \mathrm{Se}_{14}$, were obtained from solidstate combination of high purity elemental powders at $873 \mathrm{~K}$ for three days. Single crystal X-ray structure determination revealed that the compound crystallizes in the monoclinic space group $P 2_{1} / c$ (no. 14) and adopts the structure of Jamesonite $\left(\mathrm{FePb}_{4} \mathrm{Sb}_{6} \mathrm{~S}_{14}\right)$. The structure contains two crystallographically independent lead atoms with monocapped and bicapped trigonal prismatic coordinations, three antimony atoms located in a distorted octahedral environment and one iron atom occupying a flattened octahedral coordination. Neighboring monocapped and bicapped trigonal prims around lead atoms share faces and edges to build a corrugated layer parallel to the $a c$ plane. Octahedrally
\end{abstract}

coordinated antimony atoms share edges to form one-dimensional (1D) $\{\mathrm{SbSe}\}_{\infty}$ ribbons connecting adjacent corrugated layers. The distortion of the octahedral coordination around antimony atoms within the $\{\mathrm{SbSe}\}_{\infty}$ ribbons with the longest bond pointing towards the center of the ribbon, suggests the stereochemical activity of antimony lone-pairs with their electron clouds pointing towards the center of the $\{\mathrm{SbSe}\}_{\infty}$ ribbon. The three dimensional framework resulting from the connectivity between the corrugated layers and the $\{\mathrm{SbSe}\}_{\infty}$ ribbons, contains isolated cylindrical voids parallel to [100] which are filled by a 1D $\mathrm{Fe}_{\mathrm{n}} \mathrm{Se}_{4 \mathrm{n}+2}$ straight chain of edge-sharing $\mathrm{FeSe}_{6}$ octahedra. The crystal structure of $\mathrm{FePb}_{4} \mathrm{Sb}_{6} \mathrm{Se}_{14}$ is closely related to that of $\mathrm{FePb}_{3} \mathrm{Sb}_{4} \mathrm{Se}_{10}$ as they are formed by similar building units with different sizes.

\section{Introduction}

Complex main-group metal chalcogenides, owing to the structural diversity and flexibility associated with their low crystal symmetry, are attractive for the design and integration, at the atomic level, of multiple functionalities within a single material. This crystal engineering can lead to the discovery of novel advanced materials for next generation technologies in addition to facilitating fundamental studies of the interplay between various functionalities, which are otherwise difficult to combine in conventional solid state inorganic compounds. On one hand, main-group metal chalcogenides such as the $\mathrm{Bi}_{2} \mathrm{Te}_{3},{ }^{[1-3]} \quad \mathrm{PbTe},{ }^{[4-7]} \quad \mathrm{PbSe},{ }^{[8]} \quad \mathrm{K}_{x} \mathrm{Sn}_{6-2 x} \mathrm{Bi}_{2+x} \mathrm{Se}_{9},{ }^{[9]}$ $\mathrm{KSn}_{5} \mathrm{Bi}_{5} \mathrm{Se}_{13},{ }^{[9]} \mathrm{AgSn}_{m} \mathrm{SbTe}_{m+2},{ }^{[10]} \mathrm{CsMBi}_{3} \mathrm{Te}_{6},{ }^{[11]}$ and $\mathrm{CsM}_{2} \mathrm{Bi}_{3} \mathrm{Te}_{7}(\mathrm{M}=\mathrm{Pb}, \mathrm{Sn})^{[11]}$ systems are semiconductors combining low thermal conductivity with moderate thermopower and electrical conductivity. These functionalities are desirable for high performance thermoelectric materials for refrigeration and power generation applications. ${ }^{[7,12]}$ On the other hand, $\mathrm{CuSb}(\mathrm{S}, \mathrm{Se})_{2}{ }^{[13,14]}$ phases and thin film materials from the (Pb,Sn)-(Sb,Bi)-S systems ${ }^{[14-17]}$ combine optical and electrical properties, which are useful in photovoltaics. In addition, main-group metal chalcogenides such as $\mathrm{AgSbS}_{2},{ }^{[18]}$ $\mathrm{AgAsS}_{2},{ }^{[19]}$ and $\mathrm{K}_{1-x} \mathrm{Rb}_{x} \mathrm{Sb}_{5} \mathrm{~S}_{8},{ }^{[20]}$ because of the large difference in the optical and electrical conductivity between the

\footnotetext{
* Prof. P. F. P. Poudeu

Fax: +1-734-763-4788

Email: ppoudeup@umich.edu

[a] Laboratory for Emerging Energy and Electronic Materials $\left(\mathrm{LE}^{3} \mathrm{M}\right)$ Department of Materials Science and Engineering

University of Michigan

Ann Arbor, Michigan, 48109, USA
}

amorphous and the crystalline states and the low volume change between both states, are suitable candidates for phase change memory applications.

There are currently fast growing research interests in transition metal (Fe, Mn) bearing main-group metal chalcogenides. These phases generally contain well defined magnetic substructures with various structural complexities and chemical compositions within their crystal structure. The magnetic substructures are isolated from each other by semiconducting frameworks, with various dimensionalities, containing maingroup metal and chalcogenide elements. Several such compounds, for example, $\mathrm{MnSb}_{2}(\mathrm{~S}, \mathrm{Se})_{4},{ }^{[21,22]} \mathrm{FePb}_{3} \mathrm{Sn}_{4} \mathrm{Sb}_{2} \mathrm{~S}_{14},{ }^{[23]}$ and $(\mathrm{Mn}, \mathrm{Fe}) \mathrm{Pb}_{4} \mathrm{Sb}_{6} \mathrm{~S}_{14},{ }^{[24-26]}$ are one-dimensional (1D) antiferromagnetic semiconductors containing quasi-isolated magnetic single straight chains of edge-sharing $\mathrm{MQ}_{6}(\mathrm{M}=\mathrm{Mn}$, Fe; $\mathrm{Q}=\mathrm{S}, \mathrm{Se}$ ) octahedra separated by the main-group metal chalcogenide semiconducting framework. Recently, we observed the coexistence of a robust ferromagnetism and semiconductivity above room temperature in the $\mathrm{FeSb}_{2} \mathrm{Se}_{4}$ and $\mathrm{Fe}_{x} \mathrm{~Pb}_{4-x} \mathrm{Sb}_{4} \mathrm{Se}_{10}$ compositions. ${ }^{[27,28]}$ The coexistence of high Curie temperatures ferromagnetism and semiconductivity in these compounds is desirable for the development of promising spintronic materials. Interestingly, the low crystal symmetry associated with these ferromagnetic, semiconducting main group metal chalcogenides allows for independent alterations of the local composition of individual domains (magnetic and semiconducting substructures), paving the way for chemical manipulation, at the atomic level, of the nature of majority carriers (electrons, holes), their density, and mobility. This could also enable systematic investigations of elementary in- 
teractions between charge carriers and localized magnetic moments within a single crystal structure. For instance, the band gap of the magnetic and semiconducting chalcogenides can be tuned from values lower than $0.1 \mathrm{eV}$ to values as high as 2.0 $\mathrm{eV}$ by altering the nature of the chalcogenide atom $(\mathrm{S}, \mathrm{Se}$, or $\mathrm{Te}$ ) and/or by isoelectronic substitutions at the main-group metal positions within the crystal structure. For example, the band gap of $\mathrm{MnSb}_{2} \mathrm{Q}_{4}$ changes from $0.7 \mathrm{eV}^{[22]}$ for $\mathrm{Q}=\mathrm{S}$ to $0.32 \mathrm{eV}$ for $\mathrm{Q}=\mathrm{Se}{ }^{[21]}$ In addition, upon substitution of antimony by bismuth in $\mathrm{MnSb}_{2} \mathrm{Se}_{4}$, the band gap of $\mathrm{MnBi}_{2} \mathrm{Se}_{4}$ further decreases to less than $0.1 \mathrm{eV}$, and the electronic conduction in the compound change from $p$-type for $\mathrm{MnSb}_{2} \mathrm{Se}_{4}$ to $n$-type for $\mathrm{MnBi}_{2} \mathrm{Se}_{4} \cdot{ }^{[21,29]} \mathrm{A}$ similar situation is observed for the $p$-type ferromagnetic semiconductor $\mathrm{FeSb}_{2} \mathrm{Se}_{4}{ }^{[27]}$ upon substitution of antimony by bismuth. These changes in the type, density and mobility of carriers within the semiconducting substructure were found to strongly affect the magnetic exchange interactions within the magnetic substructures. ${ }^{[30]}$ Therefore, a broad range of multifunctional applications are accessible via crystal engineering of the structure of maingroup metal chalcogenides. Here, we report on the crystal structure of $\mathrm{FePb}_{4} \mathrm{Sb}_{6} \mathrm{Se}_{14}$, the selenium analog of the mineral Jamesonite $\left(\mathrm{FePb}_{4} \mathrm{Sb}_{6} \mathrm{~S}_{14} \text {, band gap }=0.48 \mathrm{eV}\right)^{[24]}$ and discuss its structural relationship with $\mathrm{FePb}_{3} \mathrm{Sb}_{4} \mathrm{Se}_{10} \cdot{ }^{[28]}$

\section{Results and Discussion}

\section{Crystal Structure}

The crystal structure determination of $\mathrm{FePb}_{4} \mathrm{Sb}_{6} \mathrm{Se}_{14}$ using single crystal $\mathrm{X}$-ray diffraction indicates that the compound is isostructural with the mineral Jamesonite, $\mathrm{FePb}_{4} \mathrm{Sb}_{6} \mathrm{~S}_{14}$, ${ }^{[26]}$ crystallizing in the monoclinic space group $P 2_{1} / c$ (no. 14). The refined lattice parameters using $\mathrm{X}$-ray single crystal data show large expansions of all three lattice constant $(\Delta a / a=2.3 \%$; $\Delta b / b=3.4 \% ; \Delta c / c=5.4 \%$ ) leading to a very large unit-cell volume expansion, $\Delta V / V=11.7 \%$ when compared to the structure of $\mathrm{FePb}_{4} \mathrm{Sb}_{6} \mathrm{~S}_{14} \cdot{ }^{[26]}$ The observed $11.7 \%$ increase in the unit-cell volume of the $\mathrm{FePb}_{4} \mathrm{Sb}_{6} \mathrm{~S}_{14} / \mathrm{FePb}_{4} \mathrm{Sb}_{6} \mathrm{Se}_{14}$ system is larger than that observed in the $\mathrm{PbS} / \mathrm{PbSe}(\Delta V / V=9.6 \%)$ and $\mathrm{Sb}_{2} \mathrm{~S}_{3} / \mathrm{Sb}_{2} \mathrm{Se}_{3}(\Delta V / V=9.7 \%)$ systems, upon substitution of the small sulfur (ionic radius: $1.84 \AA$ ) atom by the larger selenium (ionic radius: $1.98 \AA$ ) atom. ${ }^{[31,32]}$

The structure of $\mathrm{FePb}_{4} \mathrm{Sb}_{6} \mathrm{Se}_{14}$ (Figure 1) contains two crystallographically independent lead atoms. $\mathrm{Pb} 1$, which is located in a seven-fold coordinated position with monocapped trigonal prismatic geometry and $\mathrm{Pb} 2$, which is located in an eight-fold coordinated position with bicapped trigonal prismatic geometry (Figure 2A). Both coordination polyhedra share faces and edges to form a corrugated layer of lead atoms parallel to the ac plane. Three crystallographically independent antimony atoms ( $\mathrm{Sb} 1, \mathrm{Sb} 2$ and $\mathrm{Sb} 3$ ) are also found in six-fold coordinated positions with distorted octahedral geometries. These octahedra around the antimony atoms share edges and corners to form a two octahedra thick and three octahedra wide onedimensional (1D) $\{\mathrm{SbSe}\}_{\infty}$ ribbon with a $\mathrm{Sb}_{2} \mathrm{Se}_{3}$ structure-type (Figure 2B). In the crystal structure (Figure 1), adjacent corru- gated layers of lead atoms are linked by the $1 \mathrm{D}-\{\mathrm{SbSe}\}_{\infty}$ ribbons via the monocapped $(\mathrm{Pb} 1)$ and bicapped $(\mathrm{Pb} 2)$ trigonal prisms on neighboring corrugated layers. The resulting threedimensional structural framework contains cylindrical voids, which are filled by a $1 \mathrm{D}\left\{\mathrm{Fe}_{\mathrm{n}} \mathrm{Se}_{4 \mathrm{n}+2}\right\}_{\infty}$ chain of edge-sharing octahedra around the iron atoms (Figure 2C).

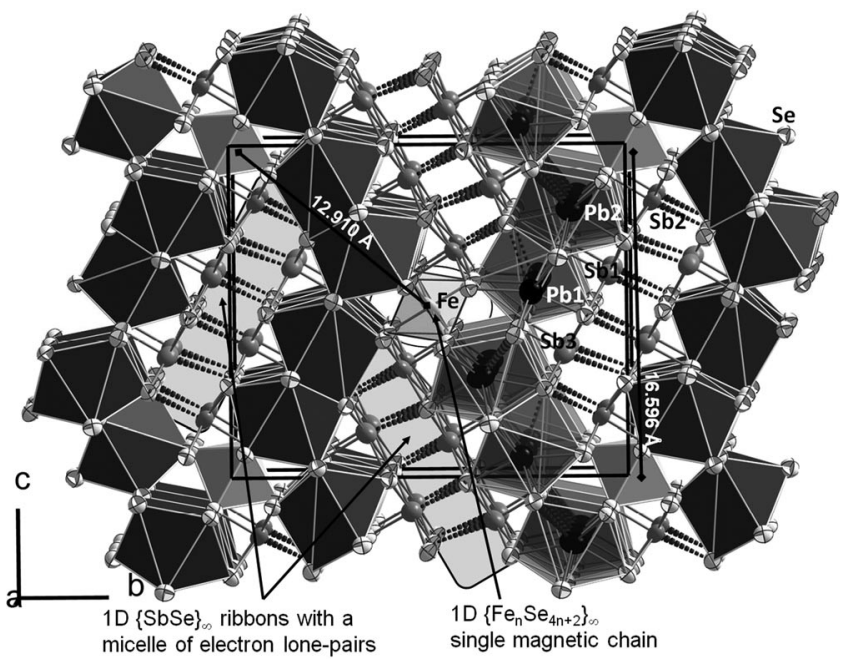

Figure 1. Graphical representation of the crystal structure of $\mathrm{FePb}_{4} \mathrm{Sb}_{6} \mathrm{Se}_{14}$ projected along [100]. Ellipsoids correspond to $98 \%$ probability level. Broken bonds indicate unusually long $\mathrm{Pb}-\mathrm{Se}$ and $\mathrm{Sb}-$ Se interatomic distances.

The crystal structure of $\mathrm{FePb}_{4} \mathrm{Sb}_{6} \mathrm{Se}_{14}$ is closely related to that of $\mathrm{FePb}_{3} \mathrm{Sb}_{4} \mathrm{Se}_{10}$, the member with $x=1$ of the newly discovered series of ferromagnetic semiconductors with general formula $\left(\mathrm{Fe}_{x} \mathrm{~Pb}_{2-x}\right) \mathrm{Pb}_{2} \mathrm{Sb}_{4} \mathrm{Se}_{10}(0 \leq x \leq 2) .{ }^{[28]}$ As highlighted in Figure 3, both crystal structures are formed by similar building units (a corrugated layer of lead atoms, a 1D$\{\mathrm{SbSe}\}$ ribbon of antimony atoms, and a 1D chain of iron atoms). The main structural differences lie on the sizes of individual building units in each structure. In the structure of $\mathrm{FePb}_{4} \mathrm{Sb}_{6} \mathrm{Se}_{14}$ the corrugated layer is one octahedron shorter than the corresponding layer in the structure of $\mathrm{FePb}_{3} \mathrm{Sb}_{4} \mathrm{Se}_{10}$. Likewise, the 1D $\{\mathrm{SbSe}\}$ ribbons in $\mathrm{FePb}_{4} \mathrm{Sb}_{6} \mathrm{Se}_{14}$ (two layers of three antimony atoms) is shorter than the similar ribbons in the structure of $\mathrm{FePb}_{3} \mathrm{Sb}_{4} \mathrm{Se}_{10}$ (two layers of four antimony atoms). As a consequence of these size differences, the void in the structure of $\mathrm{FePb}_{4} \mathrm{Sb}_{6} \mathrm{Se}_{14}$ is large enough to accommodate only a single-chain $\left\{\mathrm{Fe}_{\mathrm{n}} \mathrm{Se}_{4 \mathrm{n}+2}\right\}_{\infty}$ of iron atoms, whereas a double-chain $\left\{\mathrm{Fe}_{\mathrm{n}} \mathrm{Se}_{5 \mathrm{n}}\right\}_{\infty}$ of iron atoms can be located within the corresponding voids in the structure of $\mathrm{FePb}_{3} \mathrm{Sb}_{4} \mathrm{Se}_{10}$ (Figure 3).

Careful analysis of inter-atomic bond lengths within the individual structural building blocks in the structure of $\mathrm{FePb}_{4} \mathrm{Sb}_{6} \mathrm{Se}_{14}$ (Figure 1) revealed strong distortions of the coordination polyhedra from the ideal geometry, and anisotropic changes in corresponding bond lengths when compared to the structure of $\mathrm{FePb}_{4} \mathrm{Sb}_{6} \mathrm{~S}_{14}$ (Table 1). For instance, the monocapped trigonal prism in $\mathrm{FePb}_{4} \mathrm{Sb}_{6} \mathrm{Se}_{14}$ contains six $\mathrm{Pb} 1-\mathrm{Se}$ bonds with lengths ranging from $2.945(4)$ to $3.173(4) \AA$. The corresponding bonds in $\mathrm{FePb}_{4} \mathrm{Sb}_{6} \mathrm{~S}_{14}$ are 2.3 to $3.6 \%$ shorter. $\mathrm{The} \mathrm{Pb}-\mathrm{Se} 7$ bond completing the coordination polyhedron to 
(A)

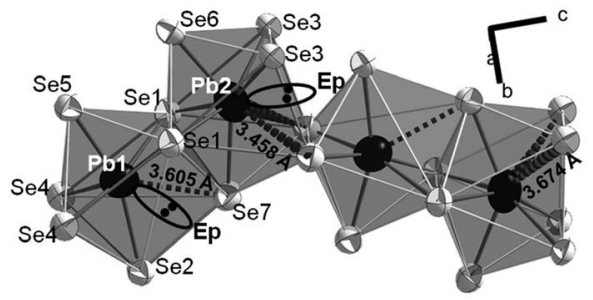

(B)

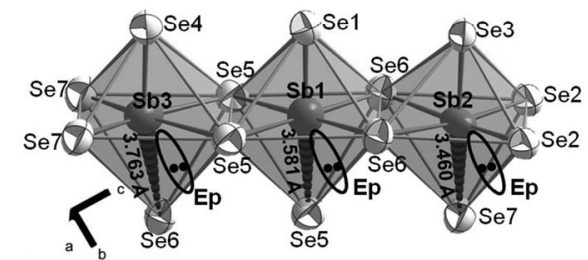

(C)

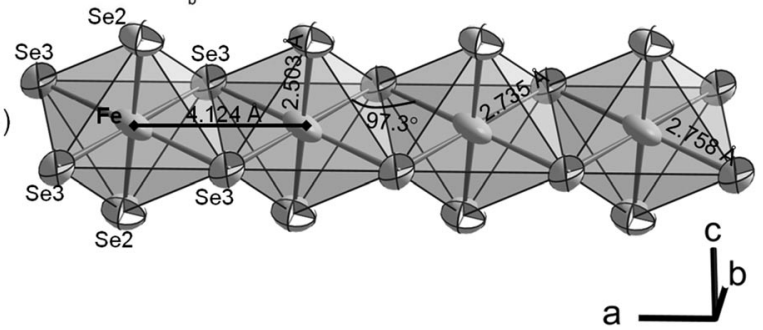

Figure 2. Atom connectivity and geometrical details of coordination polyhedra around metal atoms in the structure of $\mathrm{FePb}_{4} \mathrm{Sb}_{6} \mathrm{Se}_{14}$. (A) monocapped trigonal prismatic coordination around $\mathrm{Pb} 1$ and bicapped trigonal prismatic coordination around $\mathrm{Pb} 2$. (B) Chain of edge-sharing distorted octahedral around $\mathrm{Sb} 1, \mathrm{Sb} 2$ and $\mathrm{Sb} 3$ atoms. (C) Single chain of edge-sharing $[2+2+2]$ flattened octahedral coordination around the iron atom. Lone-pair electron clouds on lead and antimony atoms are also represented with their directions parallel to the longest $\mathrm{Pb}-\mathrm{Se}$ and $\mathrm{Sb}-\mathrm{Se}$ bonds (broken bonds).

a monocapped trigonal prisms is 3.604(4) $\AA$ in length, which corresponds to a $7.8 \%$ expansion when compared to the equivalent $\mathrm{Pb}-\mathrm{S}$ bond in $\mathrm{FePb}_{4} \mathrm{Sb}_{6} \mathrm{~S}_{14}$. Similar expansions of the largest $\mathrm{Pb}-\mathrm{Se}$ bonds ( $\mathrm{Pb} 2-\mathrm{Se} 4: 5.4$ to $6.5 \%)$ were observed in the bicapped trigonal prisms in $\mathrm{FePb}_{4} \mathrm{Sb}_{6} \mathrm{Se}_{14}$ when compared to the equivalent bonds in $\mathrm{FePb}_{4} \mathrm{Sb}_{6} \mathrm{~S}_{14}$. The corresponding $\mathrm{Pb}-\mathrm{Se}$ bond lengths in the structure of $\mathrm{FePb}_{3} \mathrm{Sb}_{4} \mathrm{Se}_{10}$ range from 2.926(9) to 3.520(6) $\AA$ (Table 1).
The examination of $\mathrm{Sb}-\mathrm{Se}$ bond lengths within the 1D $\{\mathrm{SbSe}\}_{\infty}$ ribbon, revealed a severe elongation of one of the axial $\mathrm{Sb}-\mathrm{Se}$ bonds (with lengths ranging from 3.459(4) to 3.763(4) $\AA$ ) within the octahedral coordination compared to the remaining $\mathrm{Sb}-\mathrm{Se}$ bonds with distances ranging from 2.600(4) to 3.260(4) A. This suggests a stereochemical activity of the antimony electron lone-pair with the electron cloud pointing toward the center of the $\{\mathrm{SbSe}\}_{\infty}$ slab. A similar trend in the distribution of $\mathrm{Sb}-\mathrm{Se}$ bond lengths was observed in the structure of $\mathrm{FePb}_{3} \mathrm{Sb}_{4} \mathrm{Se}_{10}$ (Table 1). The unusually long SbSe bond, originating from the stereochemical activity of the antimony lone-pair, results in the bond valence sum (BVS) calculations for antimony atoms deviating from the expected theoretical value of 3.0 (Table 2). The lone-pair electron clouds on neighboring antimony atoms, form a micelle similar to the one observed in the structure of $\mathrm{FePb}_{4} \mathrm{Sb}_{6} \mathrm{~S}_{14}{ }^{[26]}$ and $\mathrm{FePb}_{3} \mathrm{Sb}_{4} \mathrm{Se}_{10}$, ${ }^{[28]}$ within the center of the $\{\mathrm{SbSe}\}_{\infty}$ ribbon in the structure of $\mathrm{FePb}_{4} \mathrm{Sb}_{6} \mathrm{Se}_{14}$ (Figure 1).

Within the 1D $\left\{\mathrm{Fe}_{\mathrm{n}} \mathrm{Se}_{4 \mathrm{n}+2}\right\}_{\infty}$ single chain of edge-sharing $[2+2+2]$ distorted octahedra found in the structure of $\mathrm{FePb}_{4} \mathrm{Sb}_{6} \mathrm{Se}_{14}$, the $\mathrm{Fe}-\mathrm{Se}$ bond lengths range from 2.503(3) to 2.758(3) $\AA$ (Figure 2C). These bond lengths are slightly shorter than the corresponding $\mathrm{Fe}-\mathrm{Se}$ bonds (with length ranging from $2.674(2)$ to $2.924(7) \AA$ ) found within the $1 \mathrm{D}\left\{\mathrm{Fe}_{\mathrm{n}} \mathrm{Se}_{5 \mathrm{n}}\right\}_{\infty}$ double chain in the structure of $\mathrm{FePb}_{3} \mathrm{Sb}_{4} \mathrm{Se}_{10}$ (Table 1).

\section{Synthesis}

The above described structural similarities between $\mathrm{FePb}_{4} \mathrm{Sb}_{6} \mathrm{Se}_{14}$ and $\mathrm{FePb}_{3} \mathrm{Sb}_{4} \mathrm{Se}_{10}$ and their close chemical compositions, make the formation of a single-phase product of $\mathrm{FePb}_{4} \mathrm{Sb}_{6} \mathrm{Se}_{14}$ very challenging. Our efforts to synthesize this compound starting from a stoichiometric mixture of the elements and using various heating profiles including stepwise slow heating of the starting mixture to the reaction temperature (between $773 \mathrm{~K}$ and $873 \mathrm{~K}$ ) and flame reaction, did not yield a reaction product containing more than $50 \%$ of the desired phase. Preliminary analysis of the resulting polycrystalline powders using X-ray powder diffraction and differential scanning calorimetry suggested that $\mathrm{FePb}_{4} \mathrm{Sb}_{6} \mathrm{Se}_{14}$ and
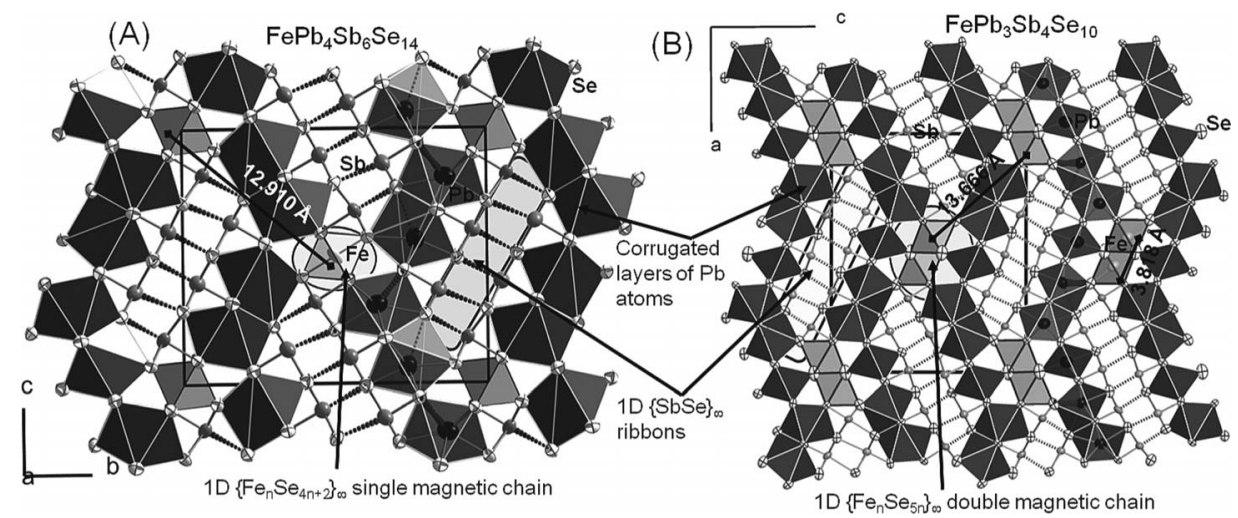

Figure 3. Structural relationships between $\mathrm{FePb}_{4} \mathrm{Sb}_{6} \mathrm{Se}_{14}(\mathrm{~A})$ and $\mathrm{FePb}_{3} \mathrm{Sb}_{4} \mathrm{Se}_{10}$ (B) highlighting the common building blocks. The corresponding voids in the structure of $\mathrm{FePb}_{3} \mathrm{Sb}_{4} \mathrm{Se}_{10}$. 
Table 1. Selected interatomic distances / $\AA$ in $\mathrm{FePb}_{4} \mathrm{Sb}_{6} \mathrm{Se}_{14}$ a) at $300 \mathrm{~K}$ compared to those of $\mathrm{FePb}_{4} \mathrm{Sb}_{6} \mathrm{~S}_{14}{ }^{[24]} \mathrm{and}_{\mathrm{FePb}} \mathrm{Sb}_{4} \mathrm{Se}_{10}{ }^{\text {[28] }}$

\begin{tabular}{|c|c|c|c|c|c|}
\hline Bond type & $\mathrm{FePb}_{4} \mathrm{Sb}_{6} \mathrm{Se}_{14}$ & $\mathrm{FePb}_{4} \mathrm{Sb}_{6} \mathrm{~S}_{14}$ & Relative expansion $1 \%$ & $\mathrm{FePb}_{3} \mathrm{Sb}_{4} \mathrm{Se}_{10}$ & \\
\hline $\mathrm{Pb} 1-\mathrm{Se} 4^{\mathrm{i}}$ & $2.945(4)$ & $2.880(4)$ & 2.3 & $\mathrm{~Pb} 1-\mathrm{Se} 2$ & $3.023(9)$ \\
\hline $\mathrm{Pb} 1-\mathrm{Se} 5$ & $2.968(4)$ & $2.886(3)$ & 2.8 & $\mathrm{~Pb} 1-\mathrm{Se} 6(2 \times)$ & $3.038(6)$ \\
\hline $\mathrm{Pb} 1-\mathrm{Se} 4$ & $2.971(4)$ & $2.891(4)$ & 2.8 & $\mathrm{~Pb} 1-\operatorname{Se} 1(2 \times)$ & $3.089(7)$ \\
\hline $\mathrm{Pb} 1-\mathrm{Se} 2$ & $3.093(4)$ & $2.987(2)$ & 3.6 & $\mathrm{~Pb} 1-\mathrm{Se} 5$ & $3.492(8)$ \\
\hline $\mathrm{Pb} 1-\mathrm{Se} 1^{\mathrm{ii}}$ & $3.141(4)$ & $3.043(3)$ & 3.2 & $\mathrm{~Pb} 1-\mathrm{Se} 8(2 \times)$ & $3.520(6)$ \\
\hline $\mathrm{Pb} 1-\mathrm{Se} 1$ & $3.173(4)$ & $3.078(3)$ & 3.1 & & \\
\hline \multirow[t]{2}{*}{$\mathrm{Pb} 1-\mathrm{Se}^{\mathrm{ii}}$} & $3.604(4)$ & $3.344(5)$ & 7.8 & $\mathrm{~Pb} 2-\operatorname{Se} 1(2 \times)$ & $3.112(6)$ \\
\hline & & & & $\mathrm{Pb} 2-\operatorname{Se} 3(2 \times)$ & $3.149(6)$ \\
\hline $\mathrm{Pb} 2-\mathrm{Se} 1^{\mathrm{i}}$ & $3.019(4)$ & $2.934(4)$ & 2.9 & $\mathrm{~Pb} 2-\mathrm{Se} 4$ & $3.192(9)$ \\
\hline $\mathrm{Pb} 2-\mathrm{Se} 1$ & $3.024(4)$ & $2.934(4)$ & 3.1 & $\mathrm{~Pb} 2-\operatorname{Se} 7(2 \times)$ & $3.252(7)$ \\
\hline $\mathrm{Pb} 2-\mathrm{Se} 6$ & $3.098(4)$ & $3.051(3)$ & 1.6 & $\mathrm{~Pb} 2-\mathrm{Se} 5$ & $3.337(8)$ \\
\hline $\mathrm{Pb} 2-\mathrm{Se} 3^{\mathrm{i}}$ & $3.151(4)$ & $3.061(3)$ & 2.9 & & \\
\hline $\mathrm{Pb} 2-\mathrm{Se} 3$ & $3.167(4)$ & $3.066(3)$ & 3.3 & $\mathrm{~Pb} 3-\mathrm{Se} 10$ & $2.926(9)$ \\
\hline $\mathrm{Pb} 2-\mathrm{Se} 7$ & $3.216(4)$ & $3.076(4)$ & 4.6 & $\mathrm{~Pb} 3-\operatorname{Se} 7(2 \times)$ & $2.942(7)$ \\
\hline Pb2-Se4 ${ }^{\text {iii }}$ & $3.457(4)$ & $3.247(4)$ & 6.5 & $\mathrm{~Pb} 3-\operatorname{Se} 6(2 \times)$ & $3.055(6)$ \\
\hline Pb2-Se4 ${ }^{\text {iv }}$ & $3.673(4)$ & $3.484(4)$ & 5.4 & $\mathrm{~Pb} 3-\mathrm{Se} 9$ & $3.133(9)$ \\
\hline $\mathrm{Sb} 1-\mathrm{Se} 1$ & $2.623(4)$ & $2.476(3)$ & 5.9 & & \\
\hline Sb1-Se6 & $2.760(4)$ & 2. $602(4)$ & 6.1 & $\mathrm{Sb} 1-\mathrm{Se} 3$ & $2.646(8)$ \\
\hline $\mathrm{Sb} 1-\mathrm{Se} 5^{\mathrm{i}}$ & $2.773(4)$ & $2.603(4)$ & 6.5 & $\operatorname{Sb} 1-\operatorname{Se} 8(2 \times)$ & $2.758(6)$ \\
\hline $\mathrm{Sb} 1-\mathrm{Se}^{\mathrm{ii}}$ & $3.081(4)$ & $3.024(4)$ & 1.9 & $\mathrm{Sb} 1-\mathrm{Se} 4(2 \times)$ & $3.038(7)$ \\
\hline Sb1-Se5 & $3.109(4)$ & $3.051(4)$ & 1.9 & Sb1-Se5 & $3.159(2)$ \\
\hline Sb1-Se5 ${ }^{v}$ & $3.581(4)$ & $3.531(4)$ & 1.4 & & \\
\hline \multirow[t]{2}{*}{$S b 1-S b 1^{v}$} & $3.961(5)$ & $3.870(2)$ & 2.4 & $\mathrm{Sb} 2-\mathrm{Se} 6$ & $2.674(9)$ \\
\hline & & & & $\mathrm{Sb} 2-\operatorname{Se} 9(2 \times)$ & $2.830(8)$ \\
\hline $\mathrm{Sb} 2-\mathrm{Se} 3^{\mathrm{vi}}$ & $2.600(4)$ & $2.447(3)$ & 6.3 & $\mathrm{Sb} 2-\operatorname{Se} 2(2 \times)$ & $3.104(7)$ \\
\hline $\mathrm{Sb} 2-\mathrm{Se} 2$ & $2.644(4)$ & $2.490(4)$ & 6.2 & $\mathrm{Sb} 2-\mathrm{Se} 2$ & $3.467(2)$ \\
\hline $\mathrm{Sb} 2-\mathrm{Se}^{\mathrm{vi}}$ & $2.892(5)$ & $2.698(4)$ & 7.2 & & \\
\hline $\mathrm{Sb} 2-\mathrm{Se} 2^{\mathrm{i}}$ & $2.927(5)$ & $2.890(3)$ & 1.3 & Sb3-Se1 & $2.640(9)$ \\
\hline $\mathrm{Sb} 2-\mathrm{Se}^{\mathrm{vii}}$ & $3.195(4)$ & $3.110(4)$ & 2.7 & $\mathrm{Sb} 3-\mathrm{Se} 4(2 \times)$ & $2.878(7)$ \\
\hline \multirow[t]{2}{*}{$\mathrm{Sb2}-\mathrm{Se}^{\mathrm{ii}}$} & $3.459(4)$ & $3.342(3)$ & 3.5 & $\operatorname{Sb} 3-\operatorname{Se} 2(2 \times)$ & $2.915(7)$ \\
\hline & & & & $\mathrm{Sb} 3-\mathrm{Se} 9$ & $3.324(9)$ \\
\hline $\mathrm{Sb} 3-\mathrm{Se} 4$ & $2.608(4)$ & $2.459(4)$ & 6.1 & & \\
\hline $\mathrm{Sb} 3-\mathrm{Se}^{\mathrm{ix}}$ & $2.654(4)$ & $2.498(4)$ & 6.2 & $\mathrm{Sb} 4-\mathrm{Se} 7$ & $2.618(9)$ \\
\hline Sb3-Se $7^{x}$ & $2.826(4)$ & $2.797(4)$ & 1.1 & $\mathrm{Sb} 4-\mathrm{Se} 5(2 \times)$ & $2.738(7)$ \\
\hline $\mathrm{Sb} 3-\mathrm{Se} 5$ & $3.115(4)$ & $2.927(4)$ & 6.4 & $\mathrm{Sb} 4-\mathrm{Se} 9(2 \times)$ & $3.206(8)$ \\
\hline $\mathrm{Sb} 3-\mathrm{Se} 5^{\mathrm{ii}}$ & $3.260(4)$ & $3.200(4)$ & 1.9 & $\mathrm{Sb} 4-\mathrm{Se} 4$ & $3.384(9)$ \\
\hline$S b 3-S b 2^{i x}$ & $3.680(3)$ & $3.604(2)$ & 2.1 & & \\
\hline \multirow[t]{2}{*}{$\mathrm{Sb3}_{-\mathrm{Se}^{\mathrm{v}}}$} & $3.763(4)$ & $3.658(3)$ & 2.9 & & \\
\hline & & & & $\mathrm{Fe} 1-\mathrm{Se} 10$ & $2.674(2)$ \\
\hline $\mathrm{Fe} 1-\mathrm{Se} 2^{\mathrm{xi}, \mathrm{xii}}$ & $2.503(3)$ & $2.377(3)$ & 5.3 & $\mathrm{Fe} 1-\mathrm{Se} 10(2 \times)$ & $2.696(9)$ \\
\hline $\mathrm{Fe} 1-\mathrm{Se} 3^{\mathrm{xiii}}$ xiv & $2.736(3)$ & $2.616(3)$ & 4.6 & $\mathrm{Fe} 1-\mathrm{Se} 8$ & $2.919(2)$ \\
\hline $\mathrm{Fe} 1-\mathrm{Se}^{\mathrm{xv}, \mathrm{xvi}}$ & $2.758(3)$ & $2.690(3)$ & 2.5 & $\mathrm{Fe} 1-\mathrm{Se} 3(2 \times)$ & $2.924(7)$ \\
\hline
\end{tabular}

a) Operators for generating equivalent atoms: (i) $-1+x, y, z$; (ii) $1+x, y, z$; (iii) $-1+x, 3 / 2-y, 1 / 2+z$; (iv) $-2+x, 3 / 2-y, 1 / 2+z$; (v) $-x$, 1-y, $-z$; (vi) $x, 1 / 2+y, 1 / 2-z$; (vii) $-1-x, 1 / 2+y, 1 / 2-z$; (viii) $x, 1+y, z$; (ix) $1+x, 3 / 2-y,-1 / 2+z$; (x) $2+x, 3 / 2-y,-1 / 2+z$; (xi) $1-x, 1-y,-z$; (xii) $x,-1+y, z$; (xiii) $1+x, 1 / 2-y,-1 / 2+z$; (xiv) $-x,-1 / 2+y, 1 / 2-z$; (xv) $x, 1 / 2-y,-1 / 2+z$; (xvi) $1-x,-1 / 2+y, 1 / 2-z$.

Table 2. Bond valence sum (BVS) calculations for $\mathrm{FePb}_{4} \mathrm{Sb}_{6} \mathrm{Se}_{14}$ and $\mathrm{FePb}_{4} \mathrm{Sb}_{6} \mathrm{~S}_{14}$ at $300 \mathrm{~K}$.

\begin{tabular}{llll}
\hline Atomic position & BVS $(\mathrm{Se})$ & BVS $(\mathrm{S})$ & Oxidation state \\
\hline $\mathrm{Pb} 1$ & 2.3 & 2.1 & $2+$ \\
$\mathrm{Pb} 2$ & 2.0 & 1.9 & $2+$ \\
$\mathrm{Sb} 1$ & 2.6 & 2.7 & $3+$ \\
$\mathrm{Sb} 2$ & 2.8 & 3.0 & $3+$ \\
$\mathrm{Sb} 3$ & 2.6 & 2.7 & $3+$ \\
$\mathrm{Fe}$ & 2.2 & 2.2 & $2+$ \\
\hline
\end{tabular}

$\mathrm{FePb}_{3} \mathrm{Sb}_{4} \mathrm{Se}_{10}$, are generally formed as the majority phases, presumably with $\mathrm{PbSb}_{2} \mathrm{Se}_{4}{ }^{[33]}$ as the third component. The exploration of additional strategies to the synthesis of high purity $\mathrm{FePb}_{4} \mathrm{Sb}_{6} \mathrm{Se}_{14}$ compound is in progress.

\section{Concluding Remarks}

In summary, we have investigated the crystal structure of $\mathrm{FePb}_{4} \mathrm{Sb}_{6} \mathrm{Se}_{14}$, the selenium analog of the mineral Jamesonite $\left(\mathrm{FePb}_{4} \mathrm{Sb}_{6} \mathrm{~S}_{14}\right)$, using single crystal X-ray diffraction data. Single crystals used for the structure determination were obtained from a solid-state reaction of the elements at $873 \mathrm{~K}$ for 3 days. The compound crystallizes in the monoclinic space group $P 2_{1} /$ $c$ (no. 14) and the structure consists of three building units: (1) corrugated layers of face and edge sharing monocapped and bicapped trigonal prisms around lead atoms, (2) $\{\mathrm{SbSe}\}_{\infty}$ ribbons of edge and corner sharing octahedra around antimony atoms, and (3) single chains, $\left\{\mathrm{Fe}_{n} \mathrm{Se}_{4 \mathrm{n}+2}\right\}_{\infty}$, of edge sharing flattened octahedra around the iron atoms. In the crystal structure, neighboring corrugated layers are linked by $\{\mathrm{SbSe}\}_{\infty}$ rib- 
bons to form a three dimensional framework with cylindrical voids parallel to [100], which are filled by the one-dimensional $\left\{\mathrm{Fe}_{\mathrm{n}} \mathrm{Se}_{4 \mathrm{n}+2}\right\}_{\infty}$ single chain. Attempts to synthesize a polycrystalline single phase product of $\mathrm{FePb}_{4} \mathrm{Sb}_{6} \mathrm{Se}_{14}$ resulted in the formation of the ferromagnetic phase, $\mathrm{FePb}_{3} \mathrm{Sb}_{4} \mathrm{Se}_{10}$, as the major impurity. The structures of both compounds are closely related and consist of similar building with different sizes. The striking similarity in the connectivity between building blocks in the structures of $\mathrm{FePb}_{4} \mathrm{Sb}_{6} \mathrm{Se}_{14}$ and $\mathrm{FePb}_{3} \mathrm{Sb}_{4} \mathrm{Se}_{10}$ and their close chemical compositions, make the synthesis of a single phase product of $\mathrm{FePb}_{4} \mathrm{Sb}_{6} \mathrm{Se}_{14}$ extremely challenging. The development of new synthetic methods for isolation of high purity $\mathrm{FePb}_{4} \mathrm{Sb}_{6} \mathrm{Se}_{14}$ phase suitable for physical property studies is underway.

\section{Experimental Section}

\section{Synthesis}

Single crystals suitable for X-ray structure determination of the $\mathrm{FePb}_{4} \mathrm{Sb}_{6} \mathrm{Se}_{14}$ phase were obtained from the combination of high purity elemental powders (Fe: $99.999 \%, \mathrm{~Pb}: 99.99 \%, \mathrm{Sb}$ : $99.999 \%$, and Se: $99.999 \%$ ) by solid-state reaction at moderate temperatures. All four components, weighed in the desired ratio (total mass $=5 \mathrm{~g}$ ) under argon atmosphere in a dry glove box, were well mixed in an agate mortar with pestle and transferred into a fused silica tube $\left(\varnothing_{\mathrm{ID}}=7 \mathrm{~mm}\right.$, Length $=18$ to $24 \mathrm{~cm}$ ) which was flame-sealed under a residual pressure of approx. $10^{-3}$ Torr. The sample was heated over $18 \mathrm{~h}$ from room temperature to $873 \mathrm{~K}$, dwelled at this temperature for $72 \mathrm{~h}$, and cooled down to room temperature in $1 \mathrm{~h}$. The resulting polycrystalline powder was ground again for further annealing. The powder sample, sealed under vacuum in a fused silica tube, was heated from room temperature to $823 \mathrm{~K}$ in $6 \mathrm{~h}$, kept at this temperature for about $72 \mathrm{~h}$ and cooled down to room temperature over $72 \mathrm{~h}$. Products from this annealing step contained several needle-like single crystals of the desired $\mathrm{FePb}_{4} \mathrm{Sb}_{6} \mathrm{Se}_{14}$ compound coexisting with several crystals of the ferromagnetic phase, $\mathrm{FePb}_{3} \mathrm{Sb}_{4} \mathrm{Se}_{10} \cdot{ }^{[28]}$ Attempts to synthesize high purity samples containing $\mathrm{FePb}_{4} \mathrm{Sb}_{6} \mathrm{Se}_{14}$ as the only magnetic phase even with non-magnetic impurity phases starting from various Fe poor nominal compositions have not been successful so far.

\section{Crystal Structure Determination}

A single crystal of $\mathrm{FePb}_{4} \mathrm{Sb}_{6} \mathrm{Se}_{14}(0.02 \times 0.03 \times 0.1 \mathrm{~mm})$ was mounted on the tip of a glass fiber using a two-component epoxy glue and intensity data were recorded at $300 \mathrm{~K}$ on a STOE IPDS-2T diffractometer using a graphite-monochromated Mo- $K_{\alpha}$ radiation $(\lambda=$ $0.71073 \AA$ A). The intensity data were best indexed in the monoclinic crystal system with unit cell parameters: $a=4.1244(2) \AA, b=$ 19.781(2) $\AA, c=16.596(3) \AA, \beta=91.6(2)^{\circ}, Z=2$. The structure was successfully solved by direct methods in the $P 2_{1} / c$ (no. 14) space group and refined by full-matrix least-squares techniques using the SHELTXL package. ${ }^{[34]}$ The structure solution revealed six metal positions and seven selenium atom positions. Since the observed unit cell parameters were similar to that of $\mathrm{FePb}_{4} \mathrm{Sb}_{6} \mathrm{~S}_{14}(a=15.750(6) \AA, b=$ 19.125(3) $\left.\AA, c=4.030(4) \AA, \beta=91.68(8)^{\circ}, Z=2\right),{ }^{[26]}$ an ordered model adapted from the atomic connectivity in the structure of $\mathrm{FePb}_{4} \mathrm{Sb}_{6} \mathrm{~S}_{14}$ was first considered. All lead atoms ( $\mathrm{Pb} 1$ and $\left.\mathrm{Pb} 2\right)$ were located at the seven-fold and eight-fold general positions $(4 e)$ forming the corrugated layer. All antimony atoms ( $\mathrm{Sb} 1, \mathrm{Sb} 2$ and $\mathrm{Sb} 3$ ) were located at the octahedral general positions ( $4 e$ ) building the NaCl-type ribbon and the unique $\mathrm{Fe}$ atom was located at the six-fold special position $2 b(1 / 2,0,0)$. The refinement of this model yielded $R_{1} \approx 8 \%$ with reasonable thermal parameters for all atoms suggesting an ordered structure for $\mathrm{FePb}_{4} \mathrm{Sb}_{6} \mathrm{Se}_{14}$. In the final refinement cycles, a secondary extinction correction and anisotropic displacement parameters for all atoms were included, resulting in a final $R_{1} \approx 2.1 \%$. The final charge balanced composition of the crystal obtained from the refinement was $\left(\mathrm{Fe}^{2+}\right)\left(\mathrm{Pb}^{+2}\right)_{4}\left(\mathrm{Sb}^{+3}\right)_{6}\left(\mathrm{Se}^{2-}\right)_{14}$. Summary of crystallographic data are given in Table 3. The atomic coordinates and isotropic displacement parameters of all atoms are given in Table 4 . Selected interatomic dis-

Table 3. Selected crystallographic data for $\mathrm{FePb}_{4} \mathrm{Sb}_{6} \mathrm{Se}_{14}$ at $300 \mathrm{~K}$.

\begin{tabular}{|c|c|}
\hline Formula sum & $\mathrm{FePb}_{4} \mathrm{Sb}_{6} \mathrm{Se}_{14}$ \\
\hline Crystal system; space group & Monoclinic; $P 2_{1} / c$ (\#14) \\
\hline Formula weight $/ \mathrm{g} \mathrm{mol}^{-1}$ & 2720.55 \\
\hline Density Calc. $/ \mathrm{g} \mathrm{cm}^{-3}$ & 6.68 \\
\hline \multicolumn{2}{|l|}{ Lattice parameters /Å } \\
\hline$a$ & $4.1244(2)$ \\
\hline$b$ & $19.781(2)$ \\
\hline$c$ & $16.596(3)$ \\
\hline$\beta /^{\circ}$ & $91.6(2)$ \\
\hline Volume $/ \AA^{3} ; Z$ & $1353.4(5) ; 2$ \\
\hline Crystal size /mm & $0.02 \times 0.03 \times 0.1$ \\
\hline Crystal shape, color & Needle-shape, Black \\
\hline Diffractometer & IPDS-2T (Stoe); \\
\hline Radiation / $\AA$ & $\lambda\left(\mathrm{Mo}-K_{\alpha}\right)=0.71073$ \\
\hline$\omega$ range; $\Delta \omega^{\circ} ; T / \mathrm{K}$ & $180 ; 1.0 ; 300$ \\
\hline $2 \theta_{\max }$ & $58.9^{\circ}$ \\
\hline \multirow[t]{3}{*}{ index range } & $-5 \leq h \leq 5$ \\
\hline & $-25 \leq k \leq 25$ \\
\hline & $-19 \leq l \leq 19$ \\
\hline Measured/Unique reflections & $35948 / 3746$ \\
\hline Reflections $\left(F_{\mathrm{o}}>4 \sigma\left(F_{\mathrm{o}}\right)\right)$ & 3346 \\
\hline Transmission factors & $0.18-0.37$ \\
\hline No. of parameters & 116 \\
\hline Extinction correction $x=$ & $0.00012(3)$ \\
\hline Absorption correction & $\begin{array}{l}\text { Numerical, crystal description opti- } \\
\text { mized using equivalent reflections }\end{array}$ \\
\hline$\mu / \mathrm{cm}^{-1}$ & 500 \\
\hline Diff. elec. density /e $\AA^{-3}$ & +1.23 to -0.98 \\
\hline$R_{1}\left(F_{\mathrm{o}}>4 \sigma\left(F_{\mathrm{o}}\right)\right)^{\mathrm{a})}$ & 0.020 \\
\hline$w R_{2}\left(F_{\mathrm{o}}>4 \sigma\left(F_{\mathrm{o}}\right)\right)^{\mathrm{b})}$ & 0.048 \\
\hline$R_{1}(\text { all })^{\mathrm{a})}$ & 0.021 \\
\hline$w R_{2}(\text { all })^{\mathrm{b})}$ & 0.049 \\
\hline GoF & 1.161 \\
\hline
\end{tabular}

a) $R_{1}=\Sigma|| F_{\mathrm{o}}|-| F_{\mathrm{c}} \| / \Sigma\left|F_{\mathrm{o}}\right|$; b) $w R_{2}=\left[\Sigma w\left(F_{\mathrm{o}}{ }^{2}-F_{\mathrm{c}}{ }^{2}\right)^{2} / \Sigma w\left(F_{\mathrm{o}}{ }^{2}\right)^{2}\right]^{1 / 2}$.

Table 4. Wyckoff positions, atomic coordinates and equivalent isotropic displacement parameters $\left(U_{\text {eq }} / 10^{-4} \times \AA^{2}\right)$ for all atoms in the asymmetric unit of $\mathrm{FePb}_{4} \mathrm{Sb}_{6} \mathrm{Se}_{14}$ at $300 \mathrm{~K}$.

\begin{tabular}{llllll}
\hline Atom & Site & $x$ & $y$ & $z$ & $U_{e q}$ \\
\hline $\mathrm{Pb} 1$ & $4 e$ & $0.4511(4)$ & $0.7358(2)$ & $0.0661(2)$ & $317(4)$ \\
$\mathrm{Pb} 2$ & $4 e$ & $-0.5282(4)$ & $0.6358(2)$ & $0.3095(2)$ & $317(4)$ \\
$\mathrm{Sb} 1$ & $4 e$ & $-0.0945(6)$ & $0.5467(2)$ & $0.1023(2)$ & $248(6)$ \\
$\mathrm{Sb} 2$ & $4 e$ & $0.0686(6)$ & $0.9337(2)$ & $0.1781(2)$ & $225(6)$ \\
$\mathrm{Sb} 3$ & $4 e$ & $0.9093(6)$ & $0.6591(2)$ & $-0.1349(2)$ & $257(6)$ \\
$\mathrm{Fe} 1$ & $2 b$ & $1 / 2$ & 0 & 0 & $221(9)$ \\
$\mathrm{Se} 1$ & $4 e$ & $-0.0419(8)$ & $0.6618(2)$ & $0.1800(2)$ & $183(8)$ \\
$\mathrm{Se} 2$ & $4 e$ & $0.5107(9)$ & $0.8914(2)$ & $0.0774(2)$ & $200(8)$ \\
$\mathrm{Se} 3$ & $4 e$ & $-0.0144(8)$ & $0.5449(2)$ & $0.4047(2)$ & $160(7)$ \\
$\mathrm{Se} 4$ & $4 e$ & $0.9420(8)$ & $0.7721(2)$ & $-0.0541(2)$ & $206(8)$ \\
$\mathrm{Se} 5$ & $4 e$ & $0.4510(9)$ & $0.5990(2)$ & $-0.0072(2)$ & $208(8)$ \\
$\mathrm{Se} 6$ & $4 e$ & $-0.5267(8)$ & $0.5012(2)$ & $0.2141(2)$ & $198(8)$ \\
$\mathrm{Se} 7$ & $4 e$ & $-0.5736(9)$ & $0.7950(2)$ & $0.2713(2)$ & $221(8)$ \\
\hline
\end{tabular}

$U_{\text {eq }}$ is defined as one-third of the trace of the orthogonalized $U_{i j}$ tensor 
tances are gathered in Table 1. To further confirm the observed distribution of the iron, lead, and antimony atoms within the various metal positions and also their assumed oxidation states, bond valence sum (BVS) calculations were carried out using bond valence parameters devised by Breese et al. ${ }^{[35]}$ Results from the BVS calculations, summarized in Table 2, are consistent with the assigned atomic positions and oxidation states. The software Diamond ${ }^{[36]}$ was utilized to create the graphic representation of the crystal structure with ellipsoid representations (98\% probability level) for all atoms. Detailed crystallographic data can be obtained from the Fachinformationszentrum Karlsruhe, 76344 Eggenstein-Leopoldshafen, Germany (Fax: +49-7247-808-666; E-Mail: crysdata@fiz.karlsruhe.de) on quoting the depository number CSD-424710.

\section{Acknowledgments}

This work was supported by the National Science Foundation (Career Award, DMR-1237550).

\section{References}

[1] D. Y. Chung, T. Hogan, P. Brazis, M. Rocci-Lane, C. Kannewurf, M. Bastea, C. Uher, M. G. Kanatzidis, Science 2000, 287, 1024.

[2] B. Poudel, Q. Hao, Y. Ma, Y. C. Lan, A. Minnich, B. Yu, X. A. Yan, D. Z. Wang, A. Muto, D. Vashaee, X. Y. Chen, J. M. Liu, M. S. Dresselhaus, G. Chen, Z. F. Ren, Science 2008, 320, 634.

[3] P. H. Soni, M. V. Hathi, C. F. DeSai, Bull. Mater. Sci. 2003, 26, 683.

[4] K. F. Hsu, S. Loo, F. Guo, W. Chen, J. S. Dyck, C. Uher, T. Hogan, E. K. Polychroniadis, M. G. Kanatzidis, Science 2004, 303, 818.

[5] P. F. P. Poudeu, J. D'Angelo, A. Downey, R. Pcionek, J. Sootsman, Z. H. Zhou, O. Palchik, T. P. Hogan, C. Uher, M. G. Kanatzidis, Mater. Res. Soc. Symp. P. 2006, 886, 195.

[6] P. F. P. Poudeu, J. D'Angelo, A. D. Downey, J. L. Short, T. P. Hogan, M. G. Kanatzidis, Angew. Chem. Int. Ed. 2006, 45, 3835.

[7] C. J. Vineis, A. Shakouri, A. Majumdar, M. G. Kanatzidis, Adv. Mater. 2010, 22, 3970 .

[8] J. Androulakis, D. Y. Chung, X. L. Su, L. Zhang, C. Uher, T. C. Hasapis, E. Hatzikraniotis, K. M. Paraskevopoulos, M. G. Kanatzidis, Phys. Rev. B 2011, 84, 155207.

[9] A. Mrotzek, M. G. Kanatzidis, Inorg. Chem. 2003, 42, 7200.

[10] M. K. Han, J. Androulakis, S. J. Kim, M. G. Kanatzidis, Adv. Energ. Mater. 2012, 2, 157.

[11] K. F. Hsu, D. Y. Chung, S. Lai, A. Mrotzek, T. Kyratsi, T. Hogan, M. G. Kanatzidis, J. Am. Chem. Soc. 2002, 124, 2410.

[12] J. R. Sootsman, D. Y. Chung, M. G. Kanatzidis, Angew. Chem. Int. Ed. 2009, 48, 8616.
[13] D. Colombara, L. M. Peter, K. D. Rogers, J. D. Painter, S. Roncallo, Thin Solid Films 2011, 519, 7438.

[14] S. Manolache, A. Duta, L. Isac, M. Nanu, A. Goossens, J. Schoonman, Thin Solid Films 2007, 515, 5957.

[15] H. Dittrich, K. Herz, Inst. Phys. Conf. Ser. 1998, 152, 293.

[16] H. Dittrich, A. Stadler, D. Topa, H. J. Schimper, A. Basch, Phys. Status Solidi A 2009, 206, 1034.

[17] P. S. Sonawane, P. A. Wani, L. A. Patil, T. Seth, Mater. Chem. Phys. 2004, 84, 221.

[18] J. Gutwirth, T. Wagner, P. Nemec, S. O. Kasap, M. Frumar, J. Non-Cryst. Solids 2008, 354, 497.

[19] T. Wagner, M. Krbal, P. Nemec, M. Frumar, T. Wagner, M. Vlcek, V. Perina, A. Mackova, V. Hnatovitz, S. O. Kasap, Appl. Phys. AMater. 2004, 79, 1563.

[20] A. Kaidatzis, J. B. Wachter, K. Chrissafis, K. M. Paraskevopoulos, M. G. Kanatzidis, J. Non-Cryst. Solids 2008, 354, 3643.

[21] H. Djieutedjeu, J. P. A. Makongo, A. Rotaru, A. Palasyuk, N. J. Takas, X. Y. Zhou, K. G. S. Ranmohotti, L. Spinu, C. Uher, P. F. P. Poudeu, Eur. J. Inorg. Chem. 2011, 3969.

[22] S. F. Matar, R. Weihrich, D. Kurowski, A. Pfitzner, V. Eyert, Phys. Rev. B 2005, 71.

[23] P. A. Salyer, L. W. ter Haar, J. Appl. Phys. 2000, 87, 6025.

[24] P. Leone, C. Doussier-Brochard, G. Andre, Y. Moelo, Phys. Chem. Miner. 2008, 35, 201.

[25] P. Leone, L. M. Le Leuch, P. Palvadeau, P. Molinie, Y. Moelo, Solid State Sci. 2003, 5, 771.

[26] Y. Matsushita, Y. Ueda, Inorg. Chem. 2003, 42, 7830.

[27] H. Djieutedjeu, P. F. P. Poudeu, N. J. Takas, J. P. A. Makongo, A. Rotaru, K. G. S. Ranmohotti, C. J. Anglin, L. Spinu, J. B. Wiley, Angew. Chem. Int. Ed. 2010, 49, 9977.

[28] P. F. P. Poudeu, N. Takas, C. Anglin, J. Eastwood, A. Rivera, J. Am. Chem. Soc. 2010, 132, 5751.

[29] D. Kurowski, PhD Thesis Thesis, University of Regensburg, Germany 2003.

[30] C. Anglin, N. Takas, J. Callejas, P. F. P. Poudeu, J. Solid State Chem. 2010, 183, 1529.

[31] R. D. Shannon, Acta Crystallogr., Sect. A 1976, 32, 751.

[32] R. D. Shannon, C. T. Prewitt, Acta Crystallogr., Sect. B 1969, 25, 925.

[33] A. Skowron, F. W. Boswell, J. M. Corbett, N. J. Taylor, J. Solid State Chem. 1994, 112, 251.

[34] G. M. Sheldrick, SHELXTL, Bruker Analytical X-ray Instruments, Inc., Madison, WI., 2000.

[35] N. E. Breese, M. O'Keeffe, Acta Crystallogr., Sect. B 1991, 47, 192.

[36] K. Brandenburg, Diamond, Crystal Impact GbR, Bonn, Germany, 2005.

Received: May 31, 2012 Published Online: September 7, 2012 